\title{
Study of the Stability of Cyanex 301 and its Salts in the Presence of Oxidizing Agents
}

\author{
Natalya A. Grigorieva*, Alexander A. Kondrasenko, \\ Isaak Yu. Fleitlikh and Nina I. Pavlenko \\ Institute of Chemistry and Chemical Technology SB RAS \\ FRC "Krasnoyarsk Science Center SB RAS" \\ Krasnoyarsk, Russian Federation
}

Received 10.01.2020, received in revised form 25.02.2020, accepted 29.03.2020

\begin{abstract}
The effect of oxidizing agents on the stability of bis (2,4,4-trimethylpentyl) dithiophosphinic acid (HR, Cyanex 301) and its extracts with $\mathrm{Cu}, \mathrm{Ni}, \mathrm{Co}$, and $\mathrm{Zn}$ in decane and toluene was studied. It was shown that the stability of $\mathrm{HR}$ and extracts varies in the following series of oxidizing agents: $\mathrm{HNO}_{3}>\mathrm{H}_{2} \mathrm{O}_{2}>\mathrm{J}_{2}$. In a mixture of Cyanex 301 with trioctylamine, the oxidation of the extractant is much more effective than with Cyanex 301 alone. The degree of degradation of Cyanex 301 is higher than that of extracts, which indicates a higher stability of HR salts in comparison with the acid itself. The main oxidation products of Cyanex 301 and its extracts $\left(\mathrm{NiR}_{2}\right.$ and $\left.\mathrm{ZnR}_{2}\right)$ with $\mathrm{HNO}_{3}, \mathrm{H}_{2} \mathrm{O}_{2}$ and $\mathrm{J}_{2}$ were determined.
\end{abstract}

Keywords: Cyanex 301, non-ferrous metal extracts, oxidation, disulfide of bis(2,4,4-trimethylpentyl) dithiophosphinic acid.

Citation: Grigorieva N.A., Kondrasenko A.A., Fleitlikh I.Yu., Pavlenko N.I. Study of the stability of Cyanex 301 and its salts in the presence of oxidizing agents, J. Sib. Fed. Univ. Chem., 2020, 13(2), 201-210. DOI: 10.17516/1998-2836-0175

(C) Siberian Federal University. All rights reserved

This work is licensed under a Creative Commons Attribution-NonCommercial 4.0 International License (CC BY-NC 4.0).

* Corresponding author E-mail address: natasha@icct.ru 


\title{
Исследование устойчивости Цианекс 301 \\ и его солей в присутствии окислителей
}

\author{
Н.А. Григорьева, А.А. Кондрасенко, \\ И.Ю. Флейтлих, Н.И. Павленко \\ Институт химии и химической технологии СО РАН \\ ФИЦ «Красноярский научный центр СО РАН» \\ Российская Федерация, Красноярск
}

Аннотация. В статье приведены данные по влиянию окислителей на устойчивость бис $(2,4,4-$ триметилпентил)дитиофосфиновой кислоты (HR, Цианекс 301) и ее экстрактов с $\mathrm{Cu}, \mathrm{Ni}, \mathrm{Co}$ и $\mathrm{Zn}$ в декане и толуоле. Показано, что устойчивость HR и экстрактов изменяется в следующем ряду окислителей: $\mathrm{HNO}_{3}>\mathrm{H}_{2} \mathrm{O}_{2}>\mathrm{J}_{2}$. В смеси Цианекс 301 с триоктиламином окисление экстрагента идет намного эффективнее, чем с одним Цианекс 301. Степень деградации Цианекс 301 выше, чем экстрактов, что свидетельствует о большей устойчивости солей HR в сравнении с самой кислотой. Определены основные продукты окисления Цианекс 301 и ее экстрактов $\left(\mathrm{NiR}_{2}\right.$ и $\mathrm{ZnR}_{2}$ ) с $\mathrm{HNO}_{3}, \mathrm{H}_{2} \mathrm{O}_{2}$ и $\mathrm{J}_{2}$.

Полученные данные могут быть полезны исследователям при изучении экстракции металлов с Цианекс 301 в различных системах.

Ключевые слова: Цианекс 301, экстракты цветных металлов, окисление, дисульфид бис $(2,4,4-$ триметилпентил)дитиофосфиновой кислоты.

Цитирование: Григорьева, Н.А. Исследование устойчивости Цианекс 301 и его солей в присутствии окислителей $/$ Н.А. Григорьева, А.А. Кондрасенко, И.Ю. Флейтлих, Н.И. Павленко // Журн. Сиб. федер. ун-та. Химия, 2020. 13(2). C. 201-210. DOI: $10.17516 / 1998-2836-0175$

\section{Введение}

Тиофосфорорганические кислоты всегда привлекали внимание исследователей в области жидкостной экстракции. Интерес к этим реагентам возрос с появлением экстрагента Цианекс 301 , активным компонентом которого является бис(2,4,4-триметилпентил)дитиофосфиновая кислота (HR) [1]. Этот экстрагент способен извлекать цветные [2], редкоземельные [3] и драгоценные [4] металлы из серно- и солянокислых растворов.

Следует добавить, что имеются вопросы, которые требуют дальнейшего рассмотрения, среди них химическая устойчивость экстрагента в различных условиях. В [5] исследована устойчивость Цианекс 301 в серной кислоте в экстремальных условиях (300 г/л $\mathrm{H}_{2} \mathrm{SO}_{4} ; 3000$ ч). Показано, что Цианекс 301 оказался очень устойчив, за период проверки не отмечено разрушения экстрагента. Отсутствие деградации наблюдалось и при его контакте с 6,0 М растворами $\mathrm{HCl}$ в течение 1250 ч [2].

Иная картина наблюдается при контакте Цианекс 301 с растворами $\mathrm{HNO}_{3}$ [5-8]. При концентрации кислоты до 2,0 моль/л и времени контакта фаз 1,0 ч $\left(\mathrm{T}=25{ }^{\circ} \mathrm{C}\right)$ разрушения экс- 
трагента не происходит. С увеличением концентрации $\mathrm{HNO}_{3}$ идет разложение экстрагента с образованием органических сульфидов, сульфоксидов и далее с разрушением алкильной цепи [5]. Согласно [6-8], первоначальным продуктом окисления Цианекс 301 является дисульфид дитиофосфиновой кислоты (R-R). В дальнейшем, с увеличением времени контакта и при более высокой концентрации $\mathrm{HNO}_{3}$, дисульфид окисляется с образованием моно- и диоксоэфиров. В качестве продуктов разложения в смеси присутствуют также Цианекс 302 и Цианекс 272. В [9] изучена фотостабильность Цианекс 301 , ее комплексов с $\mathrm{Cu}$ и Со в толуоле и гексане в ультрафиолетовой и видимой областях. После 10-часового воздействия во всех случаях обнаружено снижение содержания бис(2,4,4-триметилпентил)дитиофосфиновой кислоты и увеличение содержания Цианекс 272. Радиолитическая устойчивость Цианекс 301 исследована в [10]. Было обнаружено, что экстрагент заметно разрушается под действием $\gamma$-излучения. При дозе облучения $\leq 1 \cdot 10^{5}$ Gy продуктами разложения являются Цианекс 302 и Цианекс 272, а также другие фосфорсодержащие соединения. При дозе $\geq 1 \cdot 10^{6} \mathrm{~Gy}$ в системе появляется серная кислота.

В состав технического экстрагента входят: бис(2,4,4-триметилпентил)дитиофосфиновая кислота (77-83 \%), три(2,4,4-триметилпентилфосфинсульфид (2-4 \%), бис(2,4,4триметилпентил)монотиофосфиновая кислота (3-6 \%) и неидентифицированные примеси $(\approx 2 \%)[11]$.

Следует добавить, что если окисление Цианекс 301 ограничивается только образованием дисульфида, то вполне возможна регенерация экстрагента обработкой органической фазы восстановителем, при этом дисульфид вновь переходит в HR [2].

В настоящей работе будут рассмотрены вопросы устойчивости Цианекс 301, а также экстрагируемых комплексов металлов (Cu, $\mathrm{Ni}, \mathrm{Zn}$ и $\mathrm{Co}$ в в присутствии различных окислителей. Последнее вызвано, кроме того, возможностью проведения окислительной реэкстракции металлов с последующим переводом образовавшегося дисульфида вновь в бис(2,4,4-триметилпентил) дитиофосфиновую кислоту.

\section{Экспериментальная часть}

\section{Исходные вещества}

В работе использовали бис(2,4,4-триметилпентил)дитиофосфиновую кислоту с содержанием основного вещества 80 \% без предварительной обработки (торговое название Суanex 301) [1]. В качестве растворителей взяты толуол и декан марки «ч».

В качестве добавки использовали: триоктиламин (ТОА) с содержанием основного вещества 99 \%. Все вышеперечисленные реагенты отечественного производства, кроме экстрагентов Суanex, производителем которых является СҮТЕС (Канада).

В качестве окислителей применяли азотную кислоту, перекись водорода и йод $\left(\mathrm{J}_{2}\right)$.

Все неорганические реактивы соответствовали квалификации «х.ч.» или «ч.д.а.».

\section{Методика эксперимента}

Опыты по влиянию окислителей на устойчивость Суanex 301 и металлических экстрактов проводили путем механического перемешивания фаз при температуре $25 \pm 0,1{ }^{\circ} \mathrm{C}$ в течение 1 ч. Кислотность водной фазы варьировалась добавлением в раствор различных количеств серной кислоты.

$$
-203-
$$


Экстракты металлов получали после контакта органических растворов Cyanex 301 с водными растворами сульфатов соответствующих металлов. Отношение объемов водной и органической фаз равнялось 10 мл:10 мл, т.е. 1:1.

Органические фазы после контакта с растворами окислителей анализировали на содержание Cyanex 301 и других компонентов с помощью потенциометрического титрования, насыще-

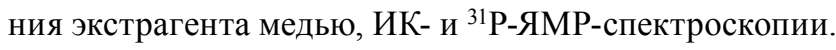

Определение металлов (Cu, Ni, Zn и Co) проводили в водной фазе с использованием атомно-абсорбционной спектроскопии. Содержание в органической фазе определяли по разности между исходным раствором и сопряженной водной фазой. В некоторых случаях проводили окислительную реэкстракцию с полным разложением экстрагента при использовании 6,0 М раствора азотной кислоты, при $\mathrm{O}: \mathrm{B}=1: 1$ в течение 30 мин.

\section{ИК- и ЯМР-спектроскопия}

ИК-спектры органических фаз записывали на ИК-Фурье спектрометре VECTOR 22 фир-

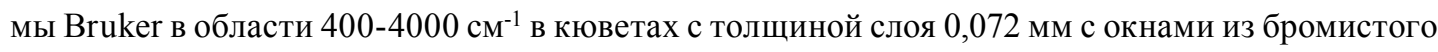
калия.

Запись спектров ЯМР производили на спектрометре Bruker AV-III 60 (частота ${ }^{31} \mathrm{P}-250$ МГц) с использованием стандартных методик. Все химические сдвиги ${ }^{31} \mathrm{P}$ даны в миллионных долях относительно внешнего стандарта $\left(85 \% \mathrm{H}_{3} \mathrm{PO}_{4}\right.$ в $\mathrm{D}_{2} \mathrm{O}\left({ }^{31} \mathrm{P}\right)$. Пики на спектрах ЯМР отнесены с использованием литературных данных [7] и данных рис. 1.

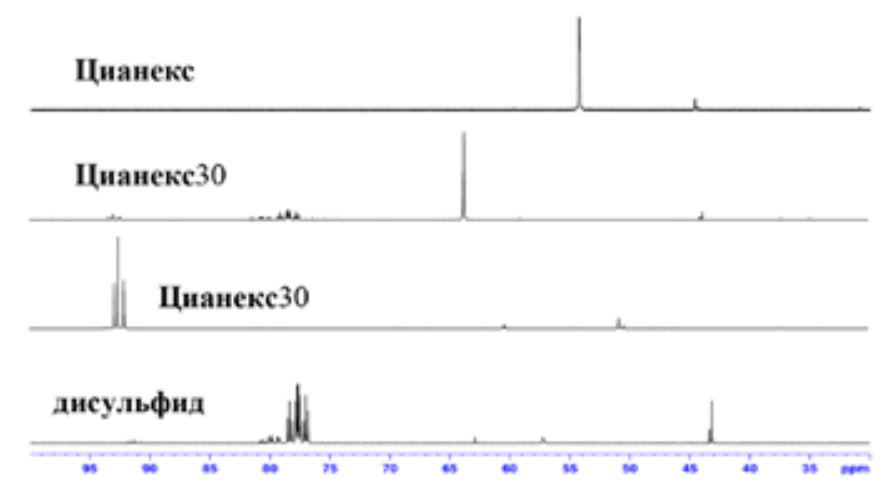

Рис. 1. ${ }^{31}$ Р ЯМР-спектры Цианекс 301, Цианекс 302, Цианекс 272 и продукта деградации Цианекс 302 (дисульфид)

Fig. 1. ${ }^{31}$ P NMR spectra of Cyanex 301, Cyanex 302, Cyanex 272, degradation product of Cyanex 301 (disulfide)

\section{Результаты и обсуждение}

Исследование устойчивости (бис(2,4,4-триметилпентил)дитиофосфиновой кислоть в присутствии азотной кислоть

Нами проведены исследования по влиянию азотной кислоты на устойчивость Цианекс 301 (HR) в толуоле и декане. Концентрация HR составляла 0,216 - 0,224 моль/л, концентрация $\mathrm{HNO}_{3}$ изменялась в интервале $0,0-10,0$ моль/л. Полученные результаты в основном согласу- 
ются с результатами других авторов [5-8]. При концентрациях $\mathrm{HNO}_{3}$ до 2,0 моль/л согласно ИК-спектрам органических фаз, а также данным потенциометрического титрования и по насыщению HR медью можно сделать вывод, что разрушения экстрагента не происходит.

$\mathrm{B}$ интервале концентраций $\mathrm{HNO}_{3}$ от 2,5 до 5 моль/л Цианекс 301 разлагается практически полностью; по данным ${ }^{31} \mathrm{P}-Я М Р$, продуктами разложения являются, в основном, дисульфид дитиофосфиновой кислоты (R-R), 82 и 1 \% и бис(2,4,4-триметилпентил)фосфиновая кислота (Цианекс 272) 12,7 - 92 \% соответственно. При этом заметного присутствия бис $(2,4,4-$ триметилпентил)монотиофосфиновой кислоты (Цианекс 302) в органической фазе отмечено не было ( $\leq 2,4$ \%). Согласно данным ИК-спектроскопии, в органической фазе обнаружено некоторое количество производных окисленной серы (сульфоксидов).

При кислотности водной фазы $\geq 5,0$ моль/л для Цианекс 301 в толуоле и $\geq 7,5$ моль/л в декане происходит практически полное превращение дитиофосфиновой кислоты в ее кислородный аналог Цианекс 272 (НА). При кислотности $\geq 5,0$ моль/л наблюдалась экстракция $\mathrm{HNO}_{3}$ в органическую фазу за счет образования сольватов типа $(\mathrm{HA})_{2} \cdot \mathrm{nHNO}_{3}$.

\section{Влияние перекиси водорода на устойчивость Цианекс 301}

Как видно на рис. 2, окисление Цианекс 301 затруднено, практически полное разрушение экстрагента реализуется при большом избытке перекиси (кр. 1). Окисление HR перекисью до дисульфида идет по следующей схеме (уравнение реакции 1):

$$
2 \mathrm{HR}+\mathrm{H}_{2} \mathrm{O}_{2} \rightarrow \mathrm{R}-\mathrm{R}+2 \mathrm{H}_{2} \mathrm{O} .
$$

Механизм этой реакции по аналогии с окислением тиолов [12], по-видимому, обусловлен тем, что HR диссоциирует с образованием дитиофосфинат-иона, который передает один электрон кислороду, в дальнейшем, димеризуясь, образует дисульфид. В присутствии $\mathrm{H}_{2} \mathrm{SO}_{4}$

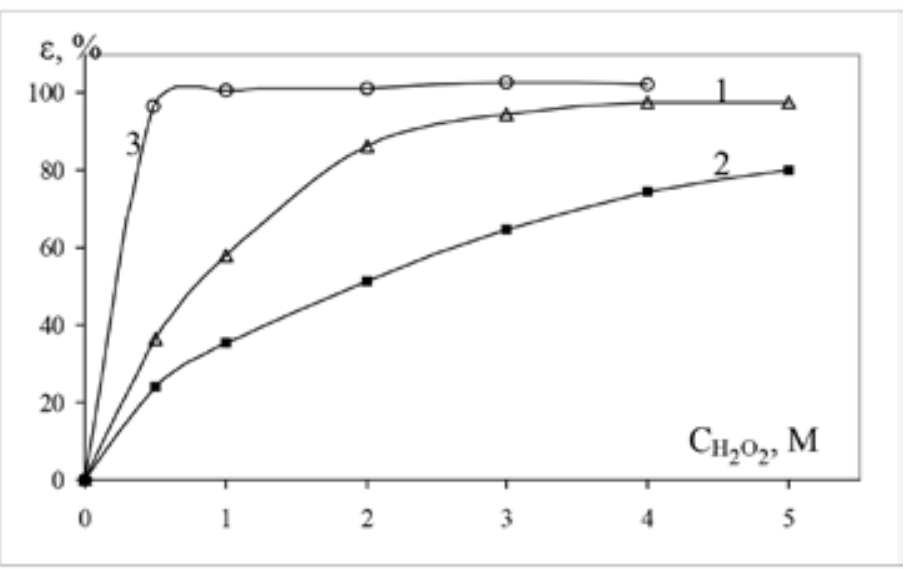

Рис. 2. Влияние перекиси водорода на степень окисления Цианекс 301 в декане в различных системах. Органическая фаза, M: 1, 2 - 0,22 HR; 3 - 0,22 HR + 0,2 TOA. Водная фаза: $1,3-\mathrm{H}_{2} \mathrm{O}_{2}$ переменной концентрации; $2-\mathrm{H}_{2} \mathrm{O}_{2}+1,0 \mathrm{MH}_{2} \mathrm{SO}_{4}$

Fig. 2. The effect of hydrogen peroxide on the oxidation degree of Cyanex 301 in decane in various systems. Organic phase, M: $1,2-0.22 \mathrm{HR} ; 3-0.22 \mathrm{HR}+0.2 \mathrm{TOA}$. Aqueous phase: $1,3-\mathrm{H}_{2} \mathrm{O}_{2}$ of variable concentration; $2-\mathrm{H}_{2} \mathrm{O}_{2}+1,0 \mathrm{MH}_{2} \mathrm{SO}_{4}$ 
Таблица 1. Составы органических фаз после контактов с растворами перекиси водорода. Исходная органическая фаза: 0,22 М Цианекс 301 в декане. Водная фаза: $\mathrm{H}_{2} \mathrm{O}_{2}$ переменной концентрации

Table 1. Compositions of organic phases after contact with hydrogen peroxide solutions. Initial organic phase: $0.22 \mathrm{M}$ Cyanex 301 in decane. Aqueous phase: $\mathrm{H}_{2} \mathrm{O}_{2}$ of variable concentration

\begin{tabular}{|c|c|c|c|c|}
\hline \multirow{2}{*}{$\begin{array}{c}\text { Концентрация } \\
\mathrm{H}_{2} \mathrm{O}_{2}, \mathrm{M}\end{array}$} & \multicolumn{4}{|c|}{ Содержание, \% } \\
\cline { 2 - 5 } & Цианекс 272 & Цианекс 301 & дисульфид & Цианекс 302 \\
\hline 0,5 & 0,0 & 57,1 & 36,69 & 5,35 \\
\hline 3,0 & 3,74 & 1,46 & 90,41 & 2,69 \\
\hline
\end{tabular}

степень диссоциации HR снижается, соответственно, уменьшается содержание дитиофосфинат-иона, в результате чего доля окисленного Цианекс 301 становится меньше (кр. 2), чем в отсутствие кислоты (кр. 1). В смеси Цианекс 301 с триоктиламином (ТОА) окисление экстрагента идет намного эффективнее, чем с одним Цианекс 301 (кр. 3). Очевидно, что это связано с катализирующим действием ТОА. Известно, что алкиламины являются катализаторами окисления тиолов перекисями или кислородом воздуха [12]. В смеси TOA и HR имеет место образование ионной пары $\left[\mathrm{TOAH}^{+}\right]\left[\mathrm{R}^{-}\right]$, где $\mathrm{R}^{-}$- дитиофосфинат-ион [13]. Такие комплексы способствуют диссоциации Цианекс 301 и, соответственно, повышают его способность к окислению.

Состав органических фаз существенно зависит от концентрации перекиси водорода. В табл. 1 приведены данные по составу органических фаз после контакта с растворами $\mathrm{H}_{2} \mathrm{O}_{2}$

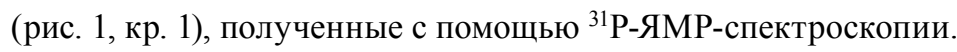

\section{Влияние перекиси водорода на устойчивость металлоэкстрактов}

с Цианекс 301

На рис. 3 приведены результаты по влиянию перекиси водорода на устойчивость медных экстрактов с Цианекс 301. Можно видеть, что сопротивление к окислению медных солей Цианекс 301 высоко, даже при относительно большом содержании $\mathrm{H}_{2} \mathrm{O}_{2}$ (4,0 моль/л) степень деградации экстрактов не превышала 14 \% (кр. 2). При введении в органическую фазу ТОА степень окисления экстрактов также остается низкой (кр. 3). Экстракция меди сопровождается восстановлением $\mathrm{Cu}(\mathrm{II})$ до $\mathrm{Cu}(\mathrm{I})$ в органической фазе. В дальнейшем комплекс $\mathrm{CuR}$ полимеризуется, что обеспечивает его высокую устойчивость [2]. Полученные данные свидетельствуют о большей устойчивости к окислению медных солей дитиофосфиновой кислоты (кр. 2 и 3) в сравнении с HR (кр. 1).

В отличие от медьсодержащих экстрактов экстракты никеля и кобальта с Цианекс 301 больше склонны к разрушению в присутствии перекиси водорода (рис. 4, кр. 1-3). Так, для никелевых экстрактов наблюдалось почти полное разрушение ( $\geq 90 \%)$ при концентрации $\mathrm{H}_{2} \mathrm{O}_{2} \geq 4,0$ моль/л (кр. 1). Очевидно, что это объясняется более низкой устойчивостью экстрагируемых комплексов никеля и кобальта $\left(\mathrm{NiR}_{2}\right.$ и $\left.\mathrm{CoR}_{2}\right)$ по сравнению с комплексами меди [2]. Необходимо отметить, что при обработке кобальтовых экстрактов перекисью, при относительно высокой концентрации $\mathrm{H}_{2} \mathrm{O}_{2}(\geq 1,0$ моль/л), органическая фаза приобретала коричневый цвет, очевидно, за счет частичного окисления Сo(II) в органической фазе до Сo(III).

$$
-206-
$$




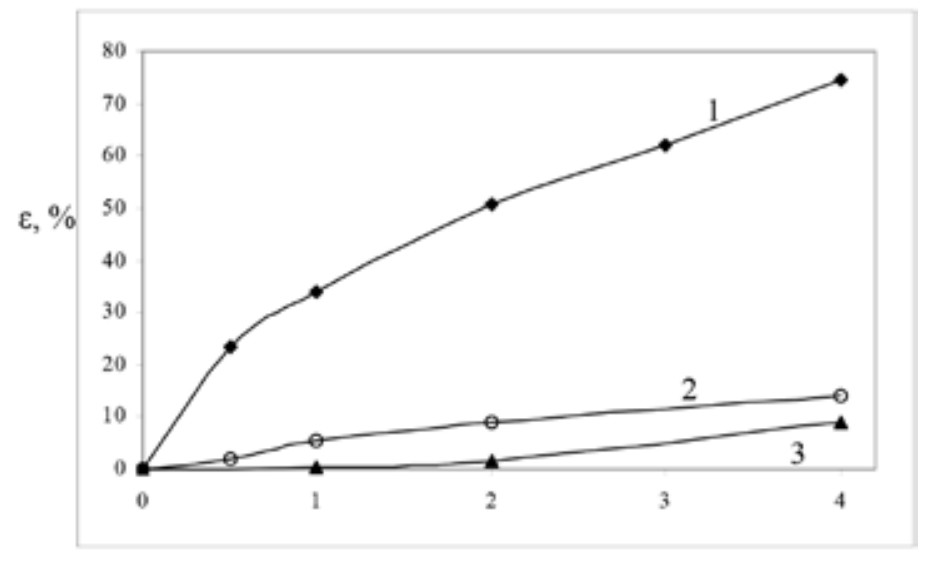

$\mathrm{C}_{\mathrm{H}_{2} \mathrm{O}_{2}}, \mathrm{M}$

Рис. 3. Влияние перекиси водорода на степень окисления экстрактов меди с Цианекс 301. Органическая фаза, M: 1 - 0,22 HR в декане; 2 - 0,22 HR в декане, насыщенный медью $(0,11 \mathrm{MCu}) ; 3-0,22 \mathrm{HR}+0,2$ TOA в толуоле, насыщенная медью $(0,11 \mathrm{MCu})$. Водная фаза, $\mathrm{M}_{2} \mathrm{H}_{2} \mathrm{O}_{2}$ переменной концентрации $+1,0 \mathrm{H}_{2} \mathrm{SO}_{4}$

Fig. 3. The oxidation of copper extracts of Cyanex 301 in the presence of hydrogen peroxide. Organic phase, M: $1-0.22 \mathrm{HR}$ in decane; $2-0.22 \mathrm{HR}$ in the decane, saturated with copper $(0.11 \mathrm{M} \mathrm{Cu}) ; 3-0.22 \mathrm{HR}+0.2 \mathrm{TOA}$ in toluene, saturated with copper $(0.11 \mathrm{MCu})$. Aqueous phase, $\mathrm{M}: \mathrm{H}_{2} \mathrm{O}_{2}$ of variable concentration $+1,0 \mathrm{H}_{2} \mathrm{SO}_{4}$

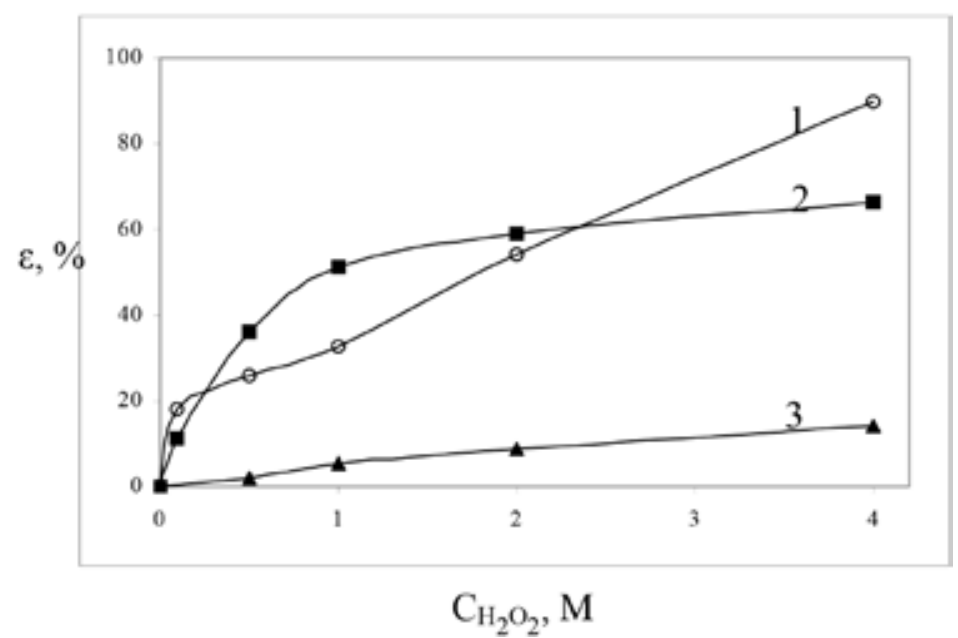

Рис. 4. Влияние $\mathrm{H}_{2} \mathrm{O}_{2}$ на степень окисления экстрактов $\mathrm{Ni}$, Со и $\mathrm{Cu}$ с Цианекс 301 в декане. Органическая фаза, М : 1 - 0,2 HR в декане, насыщенный никелем (0,1 MNi); 2 - 0,2 HR в декане, насыщенный кобальтом (0,1 MCo); 3 - 0,22 HR в декане, насыщенный медью $(0,11 \mathrm{MCu})$. Водная фаза, $\mathrm{M}_{2} \mathrm{H}_{2} \mathrm{O}_{2}$ переменной концентрации $+1,0 \mathrm{H}_{2} \mathrm{SO}_{4}$

Fig. 4. The effect of $\mathrm{H}_{2} \mathrm{O}_{2}$ on the oxidation of $\mathrm{Ni}, \mathrm{Co}$ and $\mathrm{Cu}$ extracts of Cyanex 301 in decane. Organic phase, M: $1-0.2 \mathrm{HR}$ saturated with nickel $(0,1 \mathrm{MNi}) ; 2-0.2 \mathrm{HR}$, saturated with cobalt, $(0.1 \mathrm{MCo}) ; 3-0.22 \mathrm{HR}$, saturated with copper $(0.11 \mathrm{MCu})$. Aqueous phase, $\mathrm{M}: \mathrm{H}_{2} \mathrm{O}_{2}$ of variable concentration $+1,0 \mathrm{H}_{2} \mathrm{SO}_{4}$ 
Таблица 2. Составы органических фаз после контактов с растворами $\mathrm{H}_{2} \mathrm{O}_{2}$. Исходная органическая фаза: $0,1 \mathrm{M} \mathrm{NiR}_{2}$ в декане; водная фаза, $\mathrm{M}: \mathrm{H}_{2} \mathrm{O}_{2}$ переменной концентрации $+1,0 \mathrm{H}_{2} \mathrm{SO}_{4}$

Table 2. Compositions of organic phases after contact with $\mathrm{H}_{2} \mathrm{O}_{2}$ solutions. Initial organic phase: $0.1 \mathrm{M} \mathrm{NiR}_{2}$ in decane, Aqueous phase, $\mathrm{M}: \mathrm{H}_{2} \mathrm{O}_{2}$ of variable concentration $+1,0 \mathrm{H}_{2} \mathrm{SO}_{4}$

\begin{tabular}{|c|c|c|c|c|}
\hline \multirow{2}{*}{$\begin{array}{c}\text { Концентрация } \\
\mathrm{H}_{2} \mathrm{O}_{2}, \mathrm{M}\end{array}$} & \multicolumn{4}{|c|}{ Содержание, \% } \\
\cline { 2 - 5 } & Цианекс 272 & Цианекс 301 & дисульфид & Цианекс 302 \\
\hline 1,0 & 0,0 & 62,62 & 21,49 & 8,75 \\
\hline 4,0 & 0,0 & 1,71 & 85,87 & 8,32 \\
\hline
\end{tabular}

Видимо, по этой причине при высоких концентрациях перекиси степень разложения кобальтовых экстрактов (кр. 2) оказалась меньше, чем никелевых (кр. 1), поскольку известно, что комплексы кобальта (III), $\left(\mathrm{CoR}_{3}\right)$ гораздо устойчивее комплексов никеля (II) $\left(\mathrm{NiR}_{2}\right)[2]$.

B табл. 2 приведены данные по составу органических фаз после контакта никелевых экстрактов с растворами $\mathrm{H}_{2} \mathrm{O}_{2}$ (рис. 3 , кр. 1), полученные, как и ранее, с помощью 31Р-ЯМРспектроскопии.

\section{Окисление Цианекс 301 и экстрактов никеля и цинка молекулярным йодом}

Известно, что при контакте бис(2,4,4-триметилпентил) дитиофосфиновой кислоты с йодом образуется соответствующий дисульфид [14]. На рис. 5 (кр. 1) видно, что практически полное окисление индивидуальной HR проходит уже при концентрации йода 0,1 моль/л, т.е. при мольном соотношении HR: $J_{2}=1: 0,5$, тогда как для экстрактов цинка (кр. 2) и никеля (кр. 3) не-

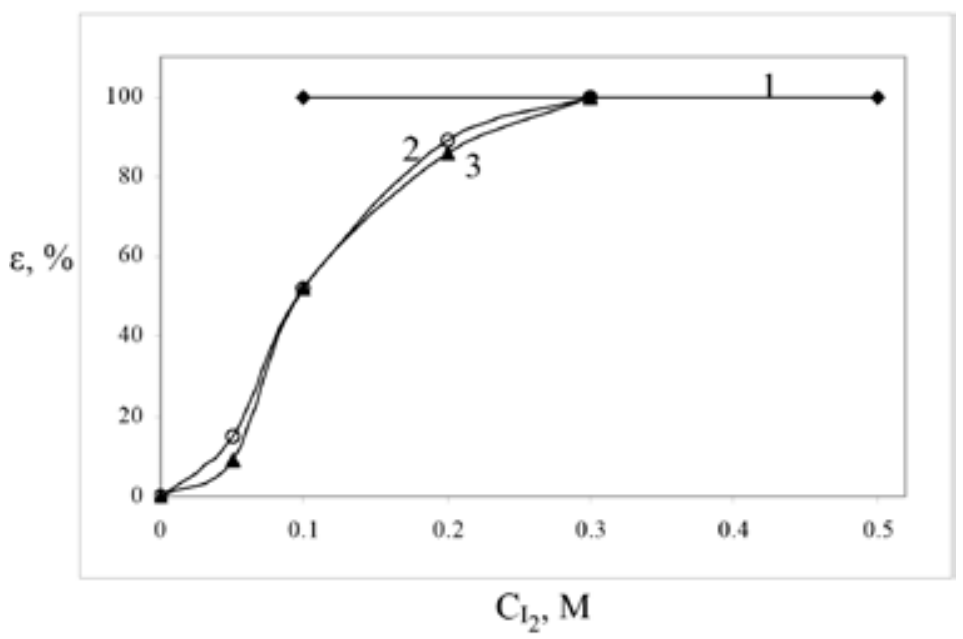

Рис. 5. Влияние концентрации $\mathrm{J}_{2}$ на степень окисления Цианекс 301 и экстрактов никеля и цинка с Цианекс 301. Органическая фаза (растворитель декан), M: 1 - 0,2 HR; 2 - 0,1 NiR $; 3$ - 0,1 ZnR2. Водная фаза: йод $\left(\mathrm{I}_{2}\right)$ в растворе $\mathrm{KJ}$

Fig. 5. Effect of $\mathrm{J}_{2}$ on the oxidation state of Cyanex 301 and nickel and zinc extracts of Cyanex 301. Organic phase (in decane), $\mathrm{M}: 1-0,2 \mathrm{HR} ; 2-0,1 \mathrm{NiR}_{2} ; 3-0,1 \mathrm{ZnR}_{2}$. Aqueous phase: iodine $\left(\mathrm{I}_{2}\right)$ in $\mathrm{KJ}$ solution

$$
-208-
$$


Таблица 3. Составы органических фаз после контактов с растворами $\mathrm{I}_{2}$. Водная фаза: йод $\left(\mathrm{I}_{2}\right)$ переменной концентрации в растворе $\mathrm{KJ}$

Table 3. Compositions of organic phases after contact with $\mathrm{I}_{2}$ solutions. Aqueous phase: iodine $\left(\mathrm{I}_{2}\right)$ of variable concentration in KJ solution

\begin{tabular}{|c|c|c|c|c|c|}
\hline \multirow{4}{*}{ 0,1M NiR 2 в декане } & \multirow{2}{*}{$\begin{array}{c}\text { Концентрация } \\
\mathrm{I}_{2}, \mathrm{M}\end{array}$} & \multicolumn{4}{|c|}{ Содержание, \% } \\
\hline & & Цианекс 272 & Цианекс 301 & дисульфид & Цианекс 302 \\
\hline & 0,1 & 0,0 & 38,81 & 48,24 & 9,0 \\
\hline & 0,2 & 0,0 & 4,87 & 83,46 & 8,68 \\
\hline \multirow{2}{*}{ 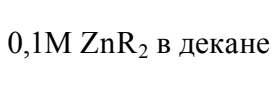 } & 0,1 & 0,0 & 37,97 & 49,81 & 8,81 \\
\hline & 0,2 & 0,0 & 4,63 & 83,98 & 8,43 \\
\hline
\end{tabular}

обходимо не менее 0,3 моль/л $\mathrm{J}_{2}$, т.е. при мольном соотношении $\mathrm{ZnR}_{2}\left(\mathrm{NiR}_{2}\right): \mathrm{J}_{2}=1: 3$. Последнее, как и ранее, свидетельствует о большей устойчивости к окислению солей дитиофосфиновой кислоты в сравнении с самой кислотой. Основными продуктами деградации дитиофосфинатов являются дисульфид дитиофосфиновой кислоты и Суаnex 302 (табл. 3).

Полученные данные свидетельствуют, что в процессах окислительной деградации имеет существенное значение тип окислителя, его концентрация, подвержен окислению сам Цианекс 301 или его смеси с добавками, например с триоктиламином. При использовании металлических экстрактов важен состав экстракта $-\mathrm{CuR}, \mathrm{NiR}_{2}$ или другой.

Соответственно, различны и составы органических фаз после контактов с окислителями. При контакте Цианекс $301 \mathrm{c} \mathrm{HNO}_{3}$ основными продуктами разложения являются дисульфид бис(2,4,4-триметилпентил)дитиофосфиновой кислоты (R-R) и бис(2,4,4-триметилпентил)фосфиновая кислота (Цианекс 272), при окислении экстрагента $\mathrm{H}_{2} \mathrm{O}_{2}$ - дисульфид, Цианекс 272 и Цианекс 302. При окислении экстрактов $\left(\mathrm{NiR}_{2}\right.$ и $\left.\mathrm{ZnR}_{2}\right)$ перекисью водорода и йодом продуктами разложения были дисульфид и Цианекс 302.

Полученные результаты свидетельствуют о трудности проведения селективной окислительной реэкстракции металлов с образованием дисульфида и последующей его регенерацией вновь до исходной бис(2,4,4-триметилпентил)дитиофосфиновой кислоты.

Данные настоящей работы будут полезны исследователям при изучении экстракции металлов с Цианекс 301 в различных системах.

\section{Благодарности / Acknowledgements}

Работа выполнена в рамках государственного задания Института химии и химической технологии СО РАН (проект АААА-А17-117021310220-0) с использованием оборудования Красноярского регионального центра коллективного пользования ФИЦ КНЦ СО РАН.

This work was conducted within the framework of the budget project AAAA-A17-117021310220-0 for Institute of Chemistry and Chemical Technology SB RAS using the equipment of Krasnoyarsk Regional Research Equipment Centre of SB RAS.

\section{Список литературы / References}

1. CYANEX $^{\circledR}$ 301, Extractant, 2020, Solvay. Technical/Product Data Sheet (TDS/PDS). 15 p.

$$
-209-
$$


2. Fleitlikh I.Yu., Grigorieva N.A., Logutenko O.A. Extraction of non-ferrous metals and iron with systems based on bis(2,4,4-trimethylpentyl)dithiophosphinic acid (CYANEX 301). Solvent Extraction and Ion Exchange. 2018. Vol. 36 (1), P. 1-21.

3. Bhattacharyya A., Mohapatra P.K., Manchanda V.K. Role of ligand softness and diluent on the separation behaviour of Am(III) and Eu(III). J. Radioanal. And Nucl. Chem., 2011. Vol. 288 (3), P. 709-716 .

4. Truong H.T., Lee M.S., Son S.H. Extraction of Palladium(II) from Hydrochloric Acid Solutions by Solvent Extraction with Mixtures Containing Either Cyanex 301 or LIX 63. Metals, 2017. Vol. 7(12), P. 541- 549.

5. Sole K.C., Hiskey B., Ferguson T.L. An Assessment of the Long-term Stabilities of Cyanex 302 and Cyanex 301 in Sulfuric and Nitric Acids. Solvent Extraction and Ion Exchange, 1993. Vol. 11 (5), P. 783-796.

6. Marc P., Gustelcean R., Klaehn J.R., Peterman D.R. Degradation Studies of Cyanex 301. Symposium of Separation Science and Tehnology for Energy Applications. October 2011, DOI: 10.13140/RG2.1.1406.9520.

7. Groenewold G.S., Peterman D.R., Klaehn J.R., Delmau L.H., Marc P., Gustelcean R. Oxidative degradation of bis(2,4,4-trimethylpentil)dithiophosphinic asid in nitric acid studied by electrospray ionization mass spectrometry. Rapid Communications in Mass Spectrometry, 2012. Vol. 26(19), P. 2195-2203.

8. Fhilippe M., Custelcean R., Groenewold G.S., Klaehn J.R., Peterman D.R., Delmau L.H. Degradation of Cyanex 301 in Contact with Nitric Acid Media. Ind. Eng. Chem. Res., 2012. Vol. 51(40), P. 13238-13244.

9. Wieszczycka K., Tomczyk W. Degradation of organothiophosphorous extractant Cyanex 301. Journal of Hazardous Materials, 2011. Vol. 192, P. 530-537.

10. Chen J., Jiao R., Zhu Y.A. Study on the Radiolytic Stability of Commercial and Purified Cyanex 301. Solvent Extraction and Ion Exchange 1996. Vol. 14(4), P. 555-565.

11. Sole C., Hyskei B. Solvent extraction characteristics of thiosubstituted organophosphinic acid extractants. Hydrometallurgy, 1992. Vol. 30, P. 345-365.

12. Оаэ С. Химия органических соединений серы. М.: Химия, 1972. 512 с. [Оae S. Chemistry of Organic Sulfur Compounds. Moscow: Khimiia, 1972. 512 p. (In Russ.)].

13. Grigorieva N.A., Pavlenko N.I., Pashkov G.L., Fleitlikh I.Yu., Nikiforova L.K. Investigation of the state of bis(2,4,4-trimethylpentyl)dithiophosphinic acid in nonane in the presence of electrondonor additives. Solvent Extraction and Ion Exchange, 2010. Vol. 28(4), P. 510-525.

14. Grigorieva N.A., FleitlikhI.Yu., Logutenko O.A. Silver extraction from hydrochloric acid solutions with the disulfide of bis(2,4,4-trimethylpentyl)dithiophosphinic acid. Solvent Extraction and Ion Exchange, 2018. Vol. 36(2), P. 162-174. 